\title{
Effect of $\mathrm{TiB}_{2}$ content on the microstructure and mechanical properties of $\mathrm{Ti}(\mathrm{C}, \mathrm{N})-\mathrm{TiB}_{2}-\mathrm{FeCoCrNiAl}$ high-entropy alloys composite cermets
}

\author{
Zhanjiang LI ${ }^{1,2}$, Chenglong ZHU ${ }^{3}$, Bingjie CAI ${ }^{1,2}$, Fa CHANG ${ }^{1,2}$, Xiaoqiang LIU $^{1,2}$, \\ Muhammad Zeeshan NAEEM ${ }^{1,2}$ and Pinqiang DAI ${ }^{1,2,3, \dagger}$ \\ ${ }^{1}$ College of Materials Science and Engineering, Fujian University of Technology, Fuzhou 350118, China \\ ${ }^{2}$ Fujian Provincial Key Laboratory of New Material Preparation and Forming Technology, Fuzhou 350108, China \\ ${ }^{3}$ School of Materials Science and Engineering, Fuzhou University, Fuzhou 350116, China
}

\begin{abstract}
Composite cermets with different mass ratios of $\mathrm{Ti}(\mathrm{C}, \mathrm{N}) / \mathrm{TiB}_{2}$ and $10 \mathrm{wt} \% \mathrm{FeCoCrNiAl}$ high-entropy alloys (HEAs) binder were fabricated by mechanical alloying and vacuum hot press sintering. The effect of the $\mathrm{TiB}_{2}$ content on the microstructure and mechanical properties of the $\mathrm{Ti}(\mathrm{C}, \mathrm{N})-\mathrm{TiB}_{2}-\mathrm{HEAs}$ cermets was systematically examined and is discussed in detail. The microstructure was analyzed by X-ray diffraction (XRD), scanning electron microscopy, and transmission electron microscopy (TEM). The results of this study show that a small amount of $\mathrm{Fe}_{2} \mathrm{~B}$ phase was detected in the XRD patterns besides the $\mathrm{Ti}(\mathrm{C}, \mathrm{N})$ and $\mathrm{TiB}_{2}$ phase. The TEM observation shows the presence of a HEAs binder phase, which was tightly bound to $\mathrm{Ti}(\mathrm{C}, \mathrm{N})$ and $\mathrm{TiB}_{2}$ phases. $\mathrm{The}$ grain size of the composite cermets gradually decreased with increasing $\mathrm{TiB}_{2}$ content increased from 0 to $45 \mathrm{wt} \%$. The relative density of the composite cermets first increased and then decreased with increasing TiB $_{2}$ content from 11.25 to $45 \mathrm{wt} \%$. When the $\mathrm{TiB}_{2}$ content reached $22.5 \mathrm{wt} \%$, the composite cermets exhibited excellent comprehensive performance. The grain size, relative density, and hard phase of the composite cermets were the dominating factors that determined the mechanical properties with increasing $\mathrm{TiB}_{2}$ content. The relative density, Vickers hardness, bending strength, and fracture toughness of the $\mathrm{Ti}(\mathrm{C}, \mathrm{N})-\mathbf{2 2 . 5} \mathrm{wt} \% \mathrm{TiB}_{2}-10 \mathrm{wt} \%$ HEAs composite cermets reached $98.86 \pm 0.20 \%, 1954.4 \pm 20 \mathrm{HV}_{10}, 727 \pm 20 \mathrm{MPa}$, and $7.9 \pm 0.1 \mathrm{MPa} \mathrm{m}^{1 / 2}$, respectively.

(ㅇ)2020 The Ceramic Society of Japan. All rights reserved.
\end{abstract}

Key-words : High entropy alloys, $\mathrm{TiB}_{2}$ content, $\mathrm{Ti}(\mathrm{C}, \mathrm{N})-\mathrm{TiB}_{2}-\mathrm{HEAs}$ composite cermets, Microstructure, Mechanical properties

[Received August 2, 2019; Accepted December 2, 2019]

\section{Introduction}

Titanium carbonitride has recently attracted significant attention owing to its excellent wear resistance, good red hardness, and low coefficient of friction, providing advantages during high speed machining. ${ }^{1)-3)}$ Traditionally, Ti(C,N)-based cermets used nickel or cobalt as the binder phases to achieve high density, toughness, ductility, and strength. ${ }^{4)-6)} \mathrm{TaC}, \mathrm{Mo}_{2} \mathrm{C}, \mathrm{WC}$, and $\mathrm{VC}$ are often added to Ti(C,N)-based cermets to enhance the wetting, sintering behavior, material hardness, and strength. ${ }^{7)-9)}$ However, the strength and toughness of $\operatorname{Ti}(\mathrm{C}, \mathrm{N})$-based cermets are usually inferior to those of the $\mathrm{WC}-\mathrm{Co}$ cemented carbides. The wettability of $\mathrm{Ni}$ binders and $\mathrm{Ti}(\mathrm{C}, \mathrm{N})$ has been poor compared to that of WC-Co hard metals, and the Co material is expensive, restricting their wide application. ${ }^{10)-13)}$

In recent years, significant efforts have been focused toward selecting a sintering binder and additive to improve the mechanical properties of $\mathrm{Ti}(\mathrm{C}, \mathrm{N})$-based ceramics.

Corresponding author: P. Dai; E-mail: pqdai@126.com
Various metallic sintering binders such as $\mathrm{Fe}$ and $\mathrm{Cr}^{14), 15)}$ were used to fabricate $\mathrm{Ti}(\mathrm{C}, \mathrm{N})$-based composite cermets. However, the inherent defects of these metals limit the properties and applications of composite cermet materials. Therefore, the selection of the binder is critical. Highentropy alloys (HEAs), a new type of multicomponent alloy, possess many excellent properties, such as a high strength, hardness, wear resistance, and thermal stability. ${ }^{16), 17)}$ Due to these excellent properties, the use of HEAs to replace traditional binders to improve the roomtemperature and high-temperature performance of composite cermets has gradually gained significant attention, and some excellent research results were achieved. ${ }^{18)-22)}$ Besides the binder, the addition of ceramic additives is a significant method to enhance the mechanical properties of $\mathrm{Ti}(\mathrm{C}, \mathrm{N})$-based ceramics. For example, the mechanical properties of $\mathrm{Ti}(\mathrm{C}, \mathrm{N})-\mathrm{TiB}_{2}$ composite material are better than those of $\mathrm{Ti}(\mathrm{C}, \mathrm{N})$ or $\mathrm{TiB}_{2}{ }^{23), 24)} \mathrm{TiB}_{2}$ has a high melting point, hardness, and modulus of elasticity, good electrical conductivity and thermal conductivity, and excellent chemical stability. ${ }^{25), 26)}$ In recent year, $\mathrm{TiB}_{2}$-based ceram- 
Table 1. Details of the starting materials parameters used for preparing $\mathrm{Ti}(\mathrm{C}, \mathrm{N})-\mathrm{TiB}_{2}-\mathrm{HEAs}$ composite cermets

\begin{tabular}{|c|c|c|c|c|}
\hline \multicolumn{2}{|c|}{ Powders } & Particle size $(\mu \mathrm{m})$ & Purity (\%) & Manufacturer \\
\hline \multicolumn{2}{|c|}{$\mathrm{Ti}(\mathrm{C}, \mathrm{N})$} & 1.00 & $\geq 99.8$ & Qinhuangdao Nuogao New Material Development Co., Ltd., China \\
\hline \multicolumn{2}{|c|}{$\mathrm{TiB}_{2}$} & 1.00 & $\geq 99.8$ & Qinhuangdao Nuogao New Material Development Co., Ltd., China \\
\hline \multirow{5}{*}{ HEAs } & $\mathrm{Fe}$ & 5.00 & $\geq 99.9$ & Shanghai Shuitian Science \& Technology Co., Ltd., China \\
\hline & $\mathrm{Co}$ & 5.00 & $\geq 99.9$ & Shanghai Shuitian Science \& Technology Co., Ltd., China \\
\hline & $\mathrm{Cr}$ & 5.00 & $\geq 99.9$ & Shanghai Shuitian Science \& Technology Co., Ltd., China \\
\hline & $\mathrm{Ni}$ & 5.00 & $\geq 99.9$ & Shanghai Shuitian Science \& Technology Co., Ltd., China \\
\hline & $\mathrm{Al}$ & 5.00 & $\geq 99.9$ & Shanghai Shuitian Science \& Technology Co., Ltd., China \\
\hline
\end{tabular}

ics have received interest of researchers owing to their excellent performance. For example, Venkateswaran et al. ${ }^{27)}$ reported $\mathrm{TiB}_{2}-6 \mathrm{wt} \% \mathrm{Cu}$ cermets with the hardness and fracture toughness of $17 \mathrm{GPa}$ and $11 \mathrm{MPam}^{1 / 2}$, respectively. $\mathrm{Wu}$ et al. ${ }^{28)}$ studied $\mathrm{TiB}_{2}-30 \mathrm{wt} \%(\mathrm{Fe}-\mathrm{Ni})$ composite cermets, and the fracture toughness was $19.26 \pm 0.72 \mathrm{MPam}^{1 / 2}$. Zhang et al. ${ }^{29)}$ fabricated $\mathrm{TiB}_{2}-$ $5 \mathrm{wt} \% \mathrm{CoCrFeNiAl} \mathrm{HEAs} \mathrm{composite} \mathrm{cermets} \mathrm{with} \mathrm{a} \mathrm{hard-}$ ness and flexural strength of $2386 \pm 18 \mathrm{HV}_{5}$ and $820 \pm 9$ $\mathrm{MPa}$, respectively. The research results showed that the CoCrFeNiAl HEAs possess outstanding wettability to $\mathrm{TiB}_{2}$ ceramics, which is the linchpin to reaching superior properties in a ceramic material.

There are a few published papers on the study of the effect of $\mathrm{TiB}_{2}$ addition on the properties of sintered Ti(C,N)-based composite cermets. Hence, in this study, FeCoCrNiAl HEAs was used as the binder in $\mathrm{Ti}(\mathrm{C}, \mathrm{N})$ based composite cermets with five different mass contents of $\mathrm{TiB}_{2}$. The effect of the $\mathrm{TiB}_{2}$ addition on the microstructure and mechanical properties of the sintered $\mathrm{Ti}(\mathrm{C}, \mathrm{N})$ based composite cermets was investigated in detail.

\section{Experimental}

\subsection{Sample preparation}

The parameters for the starting materials including particle size, purity, and manufacturer are listed in Table 1. Five samples labeled as $\mathrm{B} 0-\mathrm{B} 4$ representing various $\mathrm{Ti}(\mathrm{C}, \mathrm{N}) / \mathrm{TiB}_{2}$ mass ratios are listed in Table 2. First, the FeCoCrNiAl HEAs was prepared by mechanical alloying method. Then, the $\mathrm{Fe}, \mathrm{Co}, \mathrm{Cr}, \mathrm{Ni}$, and $\mathrm{Al}$ powders were put into a $1 \mathrm{~L}$ stainless steel vial with stainless steel grinding balls. The FeCoCrNiAl HEAs powder was synthesized at $250 \mathrm{rpm}$ with a ball-to-powder weight ratio of 15:1 under high-purity argon using a full planetary ball mill (Mickey Technology Co., Ltd., Changsha, China), followed by adding $\operatorname{Ti}(\mathrm{C}, \mathrm{N})$ and $\mathrm{TiB}_{2}$ into the stainless steel vial, and the $\mathrm{Ti}(\mathrm{C}, \mathrm{N}), \mathrm{TiB}_{2}$, and HEAs mixture powders were obtained by wet ball-milling in a planetary ball mill vial containing a stainless steel ball and ethyl alcohol as media for $15 \mathrm{~h}$ at a rotation speed of $150 \mathrm{r} / \mathrm{min}$. The mixed powder was dried at $70^{\circ} \mathrm{C}$ and passed through a 100 -mesh sieve. Finally, the obtained powders were sintered in a graphite mold (an inner diameter of $30 \mathrm{~mm}$ ). The sintering process was performed using a vacuum hot-pressing sintering (VHPS) furnace (model ZT-40-21Y, Shanghai, China) at $1500^{\circ} \mathrm{C}$ and with a $30 \mathrm{~min}$ dwell time under vacuum conditions at a pressure of $34 \mathrm{MPa}$.
Table 2. Chemical composition of the experimental Ti(C,N)$\mathrm{TiB}_{2}$-HEAs composite cermets (wt \%)

\begin{tabular}{clllllcc}
\hline & \multicolumn{3}{c}{ Compositions (wt \%) } & & \multicolumn{2}{c}{ Mass ratio } \\
\cline { 2 - 3 } \cline { 6 - 7 } & $\mathrm{Ti}(\mathrm{C}, \mathrm{N})$ & $\mathrm{TiB}_{2}$ & $\mathrm{HEAs}$ & & $\mathrm{Ti}(\mathrm{C}, \mathrm{N})$ & $\mathrm{TiB}_{2}$ \\
\hline $\mathrm{B} 0$ & 90 & 0 & 10 & & 9 & 0 \\
$\mathrm{~B} 1$ & 78.75 & 11.25 & 10 & & 7 & 1 \\
$\mathrm{~B} 2$ & 75 & 15 & 10 & & 5 & 1 \\
$\mathrm{~B} 3$ & 67.5 & 22.5 & 10 & & 3 & 1 \\
$\mathrm{~B} 4$ & 45 & 45 & 10 & & 1 & 1 \\
\hline
\end{tabular}

\subsection{Characterization}

The phase analysis of the powders and the as-sintered composite cermets was investigated by X-ray diffraction (XRD) (D8 Advance, Germany). The mixed powders, sintered composite cermets, and morphology of the fracture surface were observed by scanning electron microscopy (SEM) in the backscattered electron (BSE) mode (FEI Nova Nano SEM450, USA). Energy dispersive spectroscopy (EDS) was performed using an energy dispersive spectrometer accessory (Model Link-ISIS, Oxford, England). The microstructures of the as-prepared cermets were observed by transmission electron microscopy (TEM) (JEOL JEM-2100, Tokyo, Japan). Image J software was utilized to estimate the grain size.

The bulk density of the as-sintered samples was measured by the Archimedes principle. The hardness was tested using a Vickers hardness tester (Model HVST-10, China) with a load and loading duration of $98 \mathrm{~N}$ and $15 \mathrm{~s}$, respectively. The fracture toughness was measured via the indentation method and calculated using a Palmqvisttype crack around indentation according to the Niihara formula: ${ }^{30)}$

$$
K_{\mathrm{IC}}=0.035\left(H a^{1 / 2}\right)(E \emptyset / H)^{0.4}(l / a)^{-1 / 2} / \varnothing
$$

where $H, E, a, l$, and $\Phi$ are the Vickers hardness, elastic modulus $(480 \mathrm{GPa})$, indentation half-length, crack length and shape factor $(=3)$, respectively. The transverse rupture test was carried out using an electronic universal testing instrument (Model WD-10, China) by applying a threepoint bending method.

\section{Results and discussion}

\subsection{Morphology and phase constituents of the powders}

Figure 1 shows the SEM-EDS analysis of FeCoCrNiAl HEAs powder after $30 \mathrm{~h}$ of milling, indicating that the 
powder size after $5 \mathrm{~h}$ of milling became obviously larger than that of the original powders, attributed to cold welding effects, and portions of the alloy powder were agglomerated. With increasing milling time, the collisions, deformation, cold welding, and crushing continued to affect the alloy powder shape. These effects first decreased the particle size and then finally reach equilibrium $(10-20 \mu \mathrm{m})$ with the formation of agglomerates with an irregular orientation [Fig. 1(e)]. ${ }^{31)}$ Moreover, the EDS results show that the as-milled HEAs powder has the same composition as the designed cermets [Fig. 1(f)].

Figure 2 illustrates the SEM image and the EDS maps of the $\mathrm{Ti}(\mathrm{C}, \mathrm{N})-22.5 \mathrm{wt} \% \mathrm{TiB}_{2}-10 \mathrm{wt} \%$ HEAs composite cermet powders, indicating that the mixed powder was quite uniform after $15 \mathrm{~h}$ of wet mixing, providing sufficient wetting of the binder and ceramics phases during sintering. In general, a uniform distribution of the mixed powder has a positive effect on the microstructure and properties of the composite cermets. ${ }^{1), 14), 28)}$

\subsection{Phase constituents and microstructure of the composite cermets}

Figure 3 shows the XRD patterns of the Ti(C,N)$x$ wt $\% \mathrm{TiB}_{2}-10 \mathrm{wt} \%$ HEAs composite cermets. Clearly, with increasing $\mathrm{TiB}_{2}$ content, the intensity of $\mathrm{TiB}_{2}$ diffraction peaks also increased significantly. Apart from Ti(C,N)
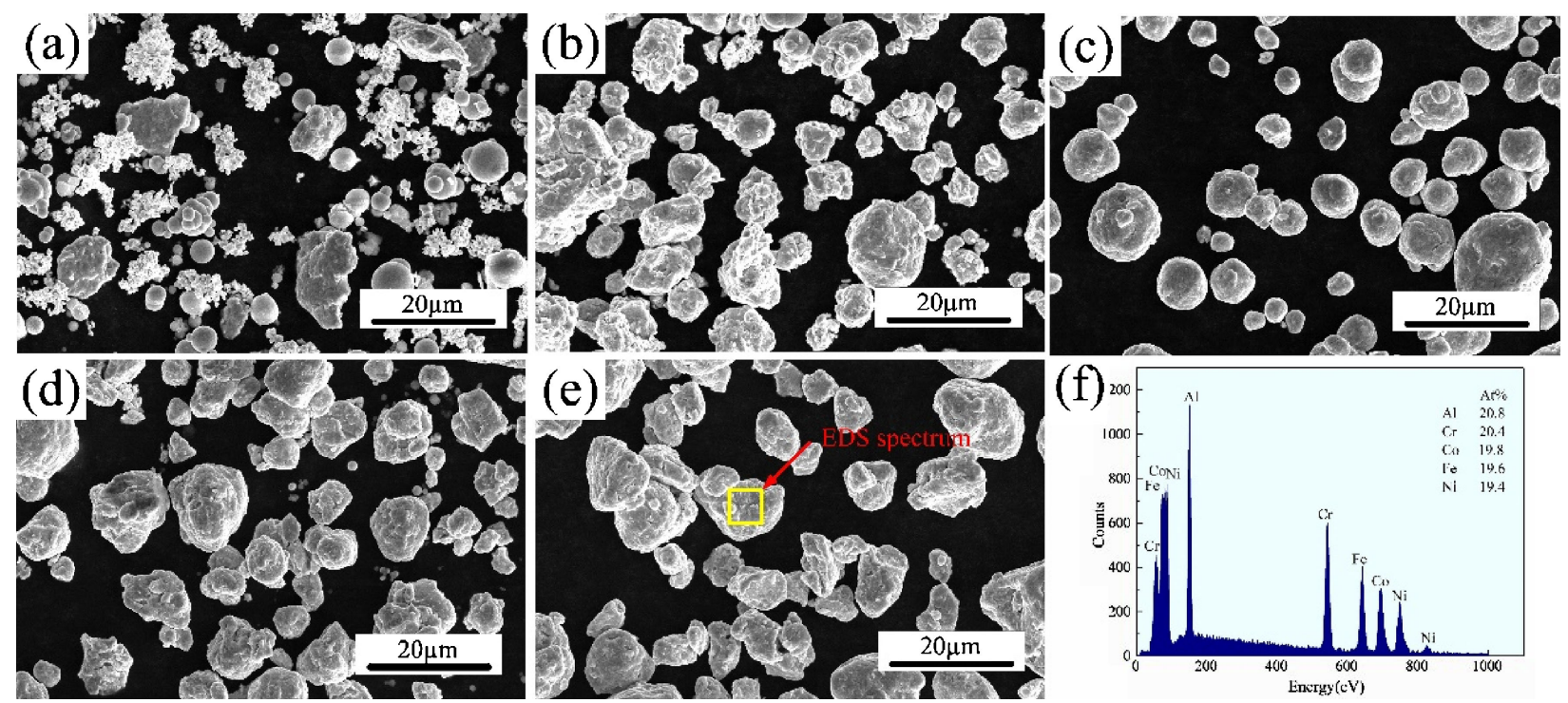

Fig. 1. SEM-EDS analysis of FeCoCrNiAl HEAs powder after $30 \mathrm{~h}$ milling. (a): $0 \mathrm{~h}$; (b): $5 \mathrm{~h}$; (c): $10 \mathrm{~h}$; (d): $20 \mathrm{~h}$; (e): $30 \mathrm{~h}$; (f): EDS analysis.
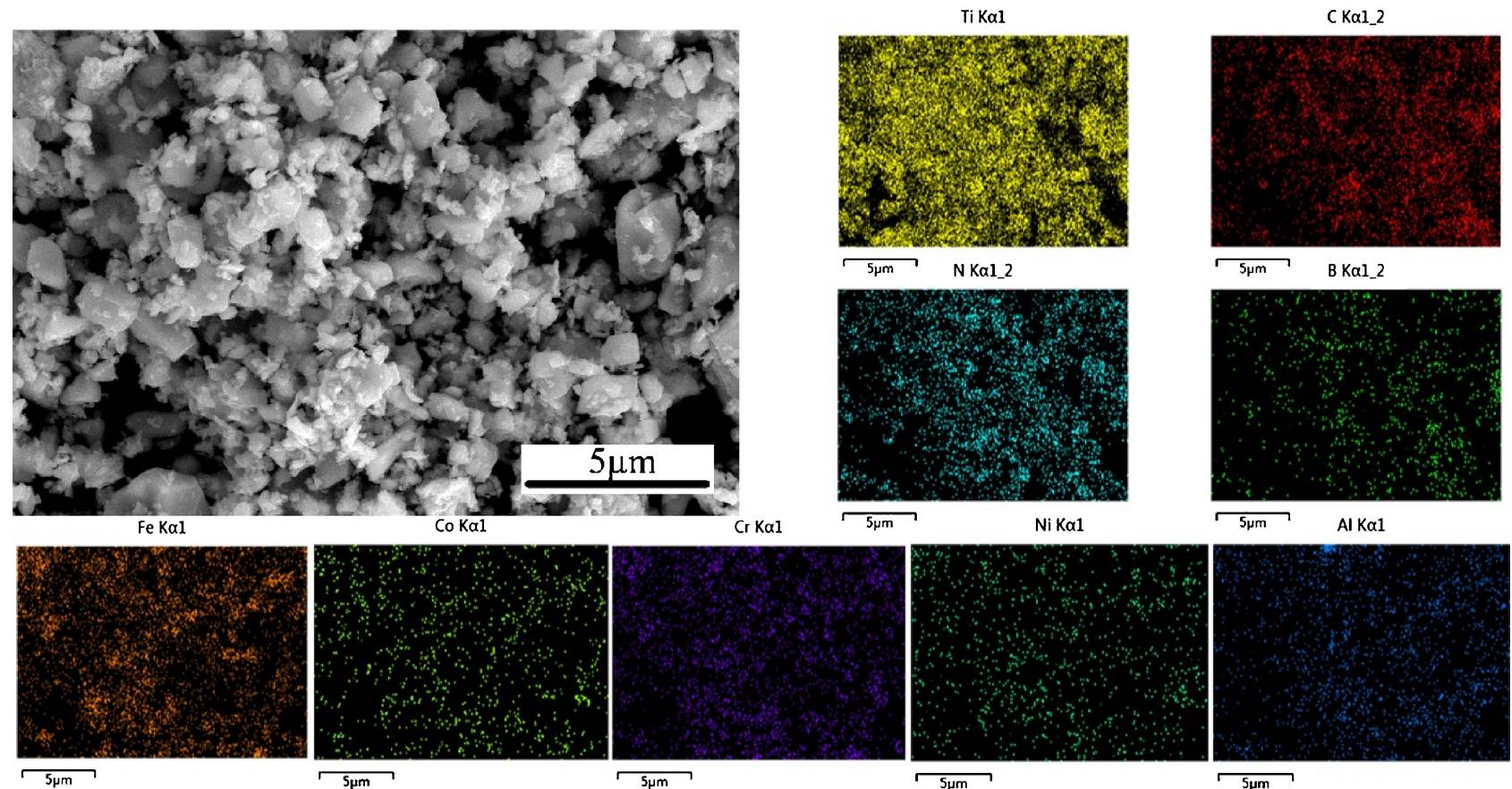

Fig. 2. SEM-EDS mapping analysis of $\mathrm{Ti}(\mathrm{C}, \mathrm{N})-22.5 \mathrm{wt} \% \mathrm{TiB}_{2}-10 \mathrm{wt} \%$ HEAs mixture powder. 


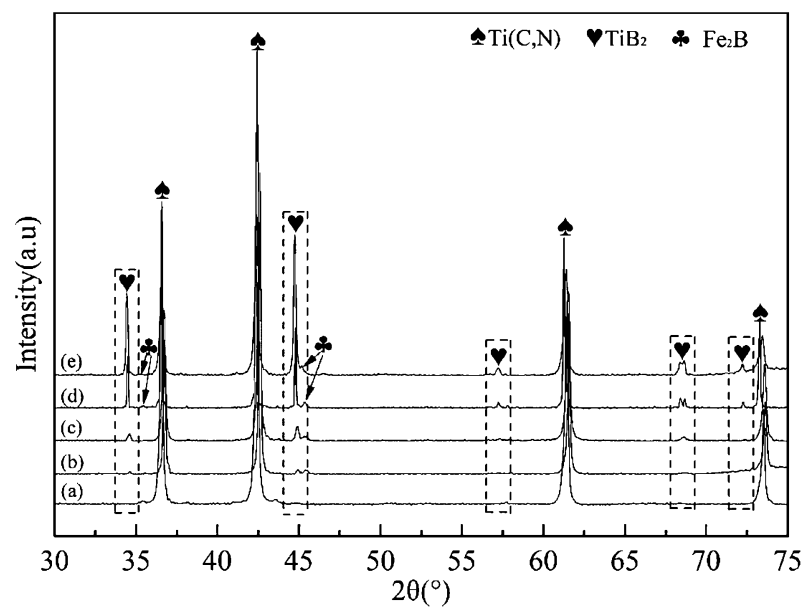

Fig. 3. XRD analysis of the sintered $\mathrm{Ti}(\mathrm{C}, \mathrm{N})-x \mathrm{TiB}_{2}-10 \mathrm{wt} \%$ HEAs composite cermets with different $\mathrm{TiB}_{2}$ mass content: (a) 0 wt $\%$, (b) $11.25 \mathrm{wt} \%$, (c) $15 \mathrm{wt} \%$, (d) $22.5 \mathrm{wt} \%$, (e) $45 \mathrm{wt} \%$. and $\mathrm{TiB}_{2}$ phases, a minor peak corresponding to $\mathrm{Fe}_{2} \mathrm{~B}$ was discovered in the XRD patterns; however, its amount is very small, because of only $2.2 \mathrm{wt} \% \mathrm{Fe}$ in the cermets. Figure 4 shows the TEM images of the Ti $(\mathrm{C}, \mathrm{N})-22.5$ wt $\% \mathrm{TiB}_{2}-10 \mathrm{wt} \%$ HEAs composite cermets. The dark granular phases were distributed between the bright phases in Fig. 4(a). The electron diffraction analysis [Fig. 4(b)] demonstrates that the dark granular phase was a singlephase BCC structure. The additional EDS maps [Fig. 4(c)] of the dark granular phase show the presence of only five elements: $\mathrm{Fe}, \mathrm{Co}, \mathrm{Cr}, \mathrm{Ni}$, and $\mathrm{Al}$, indicating the presence of the HEAs and that a phase transformation did not occur after sintering. However, in Fig. 3, the HEAs peaks are not present, attributed to the low content of the HEAs.

The SEM-BSE images of $\mathrm{Ti}(\mathrm{C}, \mathrm{N})-x$ wt $\% \quad \mathrm{TiB}_{2}-$ $10 \mathrm{wt} \%$ HEAs composite cermets are shown in Fig. 5. Clearly, the cermets are shown as four different colors. With increasing $\mathrm{TiB}_{2}$ content, the dark gray phase increased
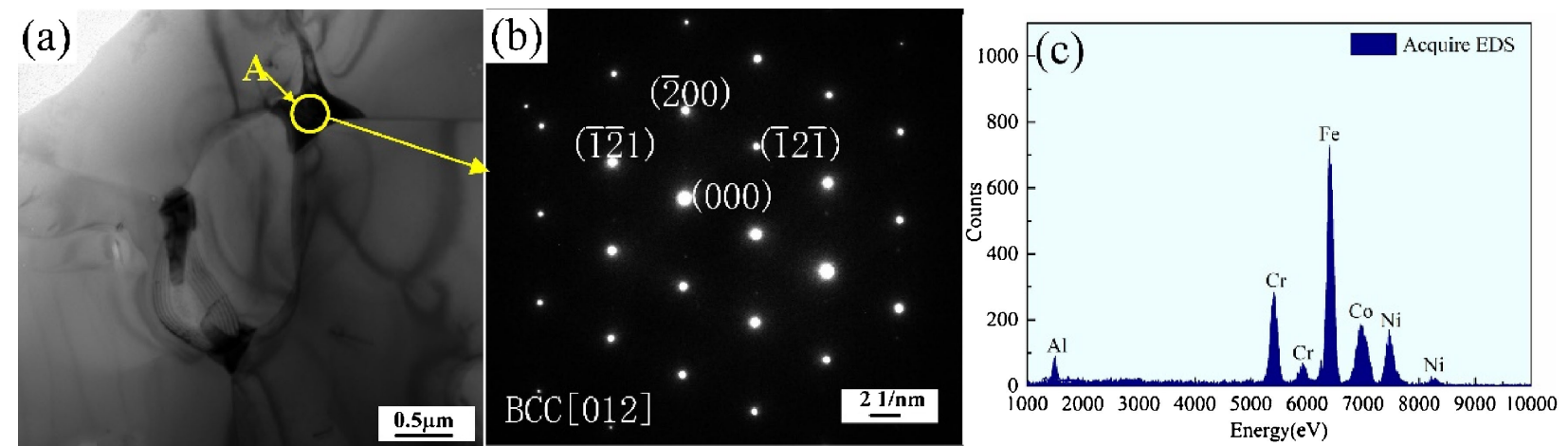

Fig. 4. TEM characterization of $\mathrm{Ti}(\mathrm{C}, \mathrm{N})-22.5 \mathrm{wt} \% \mathrm{TiB}_{2}-10 \mathrm{wt} \%$ HEAs composite cermets. (a) Bright field TEM micrograph; for the marked open circle in yellow, (b) and (c) represents the corresponding SAED pattern and EDS point analysis, respectively.
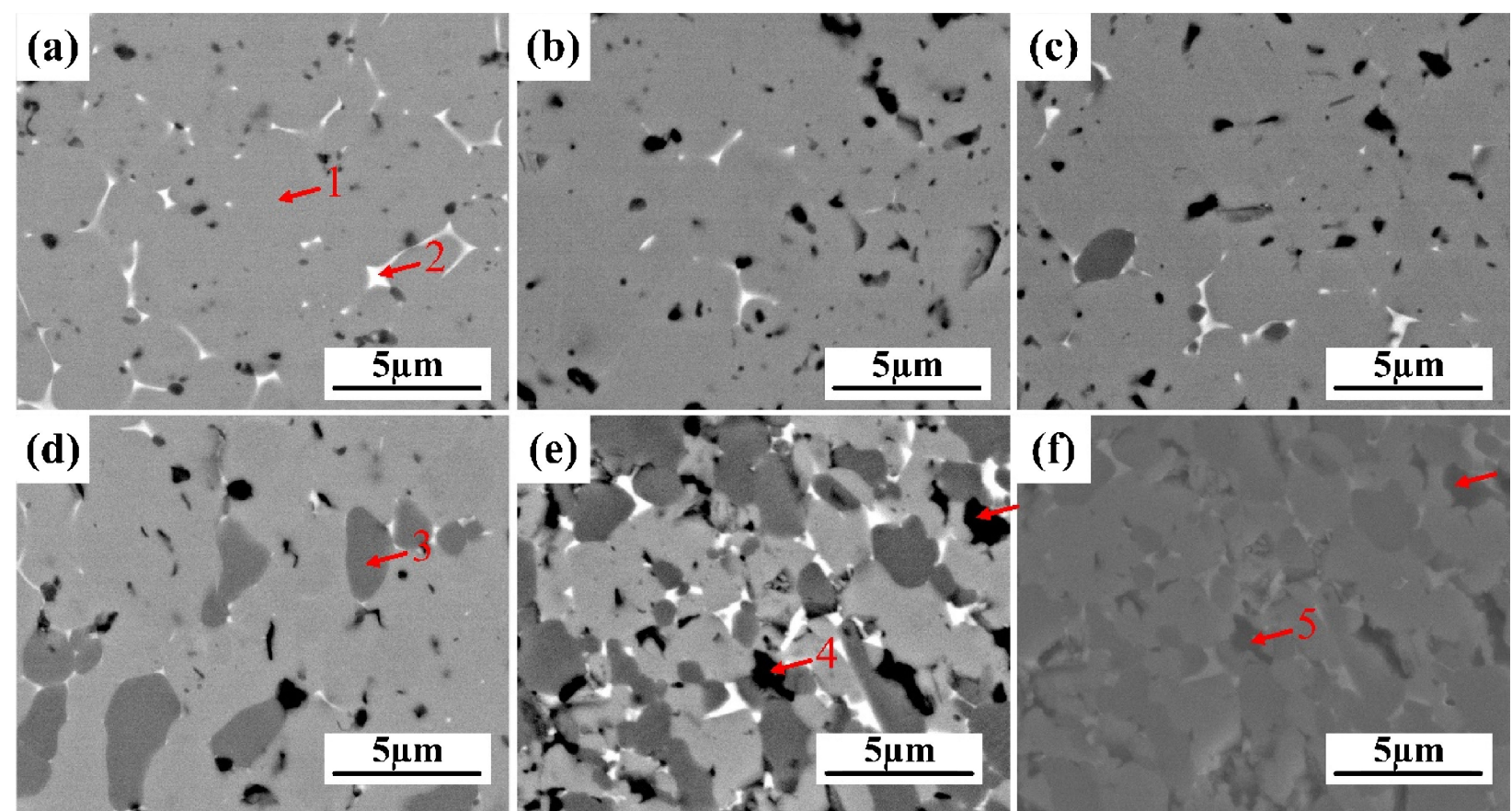

(f)

Fig. 5. SEM-BSE images of the sintered Ti(C,N)-x $\mathrm{TiB}_{2}-10 \mathrm{wt} \%$ HEAs composite cermets with different $\mathrm{TiB}_{2}$ mass content: (a) $0 \mathrm{wt} \%$, (b) $11.25 \mathrm{wt} \%$, (c) $15 \mathrm{wt} \%$, (d) $22.5 \mathrm{wt} \%$, (e) $45 \mathrm{wt} \%$. 
Table 3. Results of BSE/EDS analysis for Ti(C,N)-TiB 2 -HEAs composite cermets in Fig. 5

\begin{tabular}{|c|c|c|c|c|c|c|c|c|c|c|c|c|}
\hline \multirow{2}{*}{ Type of study } & & \multirow{2}{*}{ Location } & \multicolumn{10}{|c|}{ Element [at \%] } \\
\hline & & & $\mathrm{Ti}$ & $\mathrm{C}$ & $\mathrm{N}$ & $\mathrm{B}$ & $\mathrm{O}$ & $\mathrm{Fe}$ & Co & $\mathrm{Cr}$ & $\mathrm{Ni}$ & $\mathrm{Al}$ \\
\hline \multirow[t]{5}{*}{ BSE/EDS } & Figure 5(a) & 1 & 32.0 & 30.7 & 36.3 & - & - & - & - & 1.0 & - & - \\
\hline & & 2 & 4.1 & 3.3 & - & 1.2 & - & 19.9 & 16.8 & 18.1 & 20.7 & 15.9 \\
\hline & & 3 & 60.1 & - & - & 38.1 & - & - & - & 1.8 & - & - \\
\hline & Figure 5(e) & 4 & 2.4 & 8.1 & 8.9 & - & 29.6 & 1.0 & - & 2.3 & - & 47.7 \\
\hline & Figure 5(f) & 5 & 5.7 & 7.0 & 8.0 & - & 36.1 & 1.1 & - & 2.9 & - & 39.2 \\
\hline
\end{tabular}
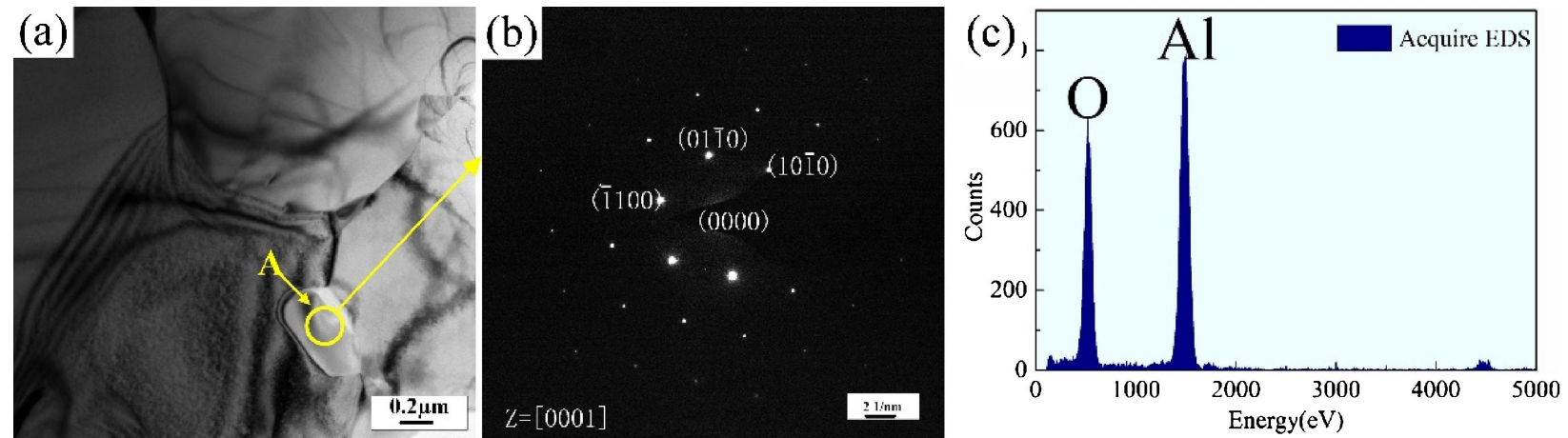

Fig. 6. TEM characterization of $\mathrm{Ti}(\mathrm{C}, \mathrm{N})-22.5 \mathrm{wt} \% \mathrm{TiB}_{2}-10 \mathrm{wt} \%$ HEAs composite cermets. (a) Bright field TEM micrograph; for the marked open circle in yellow, (b) and (c) represents the corresponding SAED pattern and EDS analysis, respectively.

gradually. The EDS analysis [regions 1,2 and 3 in Figs. 5(a) and 5(d) and Table 3] shows that the dark gray phase was $\mathrm{TiB}_{2}$, the gray phase corresponds to $\mathrm{Ti}(\mathrm{C}, \mathrm{N})$, and the relatively uniform white phase between $\mathrm{TiB}_{2}$ and $\mathrm{Ti}(\mathrm{C}, \mathrm{N})$ was the HEAs phase. However, as the $\mathrm{TiB}_{2}$ content increased from 0 to $22.5 \mathrm{wt} \%$, a small amount of black phase resembling a pore is observed as shown in Figs. 5(d) and 5(e). To confirm these black phases, Fig. 5(f) shows the secondary electron image of the same observed area in Fig. 5(e). Comparing these two images indicates that these black particles are not pores. The EDS analysis [regions 4 and 5 in Figs. 5(e) and 5(f), and Table 3] shows that these particles may be alumina particles. Figure 6 shows the TEM analysis results of the composite cermets containing $22.5 \mathrm{wt} \% \mathrm{TiB}_{2}$. Combining the EDS and electron diffraction pattern analyses confirmed that the particles were alumina. The TEM and SEM analysis results confirmed the presence of $\mathrm{Al}_{2} \mathrm{O}_{3}$ in the composite cermets, mainly due to the fact that the $\mathrm{Al}$ element in the HEAs reacts with $\mathrm{TiO}_{2}$ and $\mathrm{B}_{2} \mathrm{O}_{3}$ in $\mathrm{TiB}_{2},{ }^{32)}$ and the inevitable oxidation of the $\mathrm{Al}$ element occurs during the sintering process due to its lively nature.

\subsection{Density and mechanical properties}

Figure 7 shows the density of the $\mathrm{Ti}(\mathrm{C}, \mathrm{N})-x \mathrm{TiB}_{2}-10$ wt $\%$ HEAs composite cermets with different $\mathrm{TiB}_{2}$ contents. With increasing $\mathrm{TiB}_{2}$ content from 0 to $11.25 \mathrm{wt} \%$, the relative density decreased, because $\operatorname{Ti}(\mathrm{C}, \mathrm{N})$ is more sinterable than $\mathrm{TiB}_{2}$. With increasing $\mathrm{TiB}_{2}$ content increased to $22.5 \mathrm{wt} \%$, the relative density increased to the highest $(98.86 \%)$. This is attributed to the fact that $\mathrm{TiB}_{2}$ content affected the densification process of composite cermets. Figure 8 shows that as the $\mathrm{TiB}_{2}$ content increased

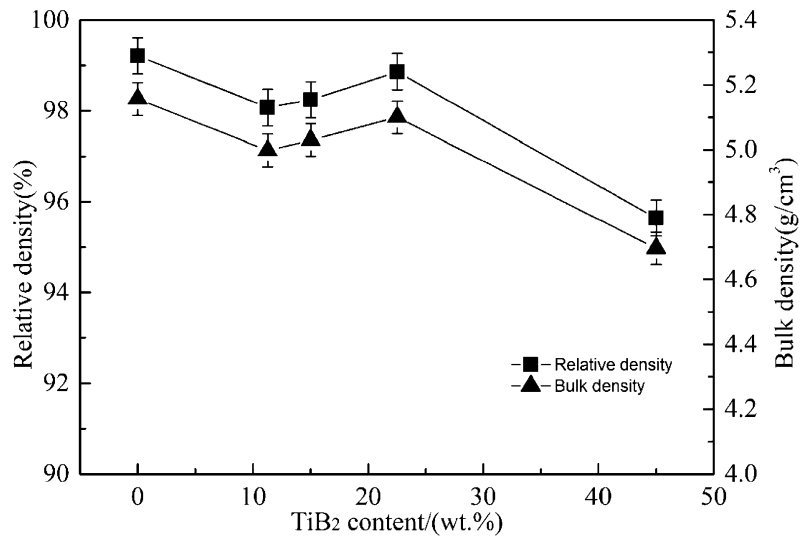

Fig. 7. Relative density and bulk density as a function of the $\mathrm{TiB}_{2}$ mass content.

from 11.25 to $22.5 \mathrm{wt} \%$, the grain size of the ceramic phase $\left[\mathrm{Ti}(\mathrm{C}, \mathrm{N})\right.$ and $\left.\mathrm{TiB}_{2}\right]$ gradually decreased. In general, when the grain is fine, its interfacial energy and sintering activity increase, both of which promote the dissolutionprecipitation, grain rearrangement particle rearrangement, and provides a sufficient amount of the composite cermets liquid phase. ${ }^{28), 33)}$ These factors can promote the densification of the composite cermets. Therefore, the composite cermets with relatively fine grains had a higher density than those with coarse grains during the liquid phase sintering; nevertheless, the starting ceramic phase had the same grain size. However, with increasing $\mathrm{TiB}_{2}$ content to $45 \mathrm{wt} \%$, the relative density decreased to $95.64 \%$. The low density is mainly attributed to the high melting point, the low diffusion coefficient, and the relatively high impurity content (oxides of titanium and boron) of the $\mathrm{TiB}_{2}$. 

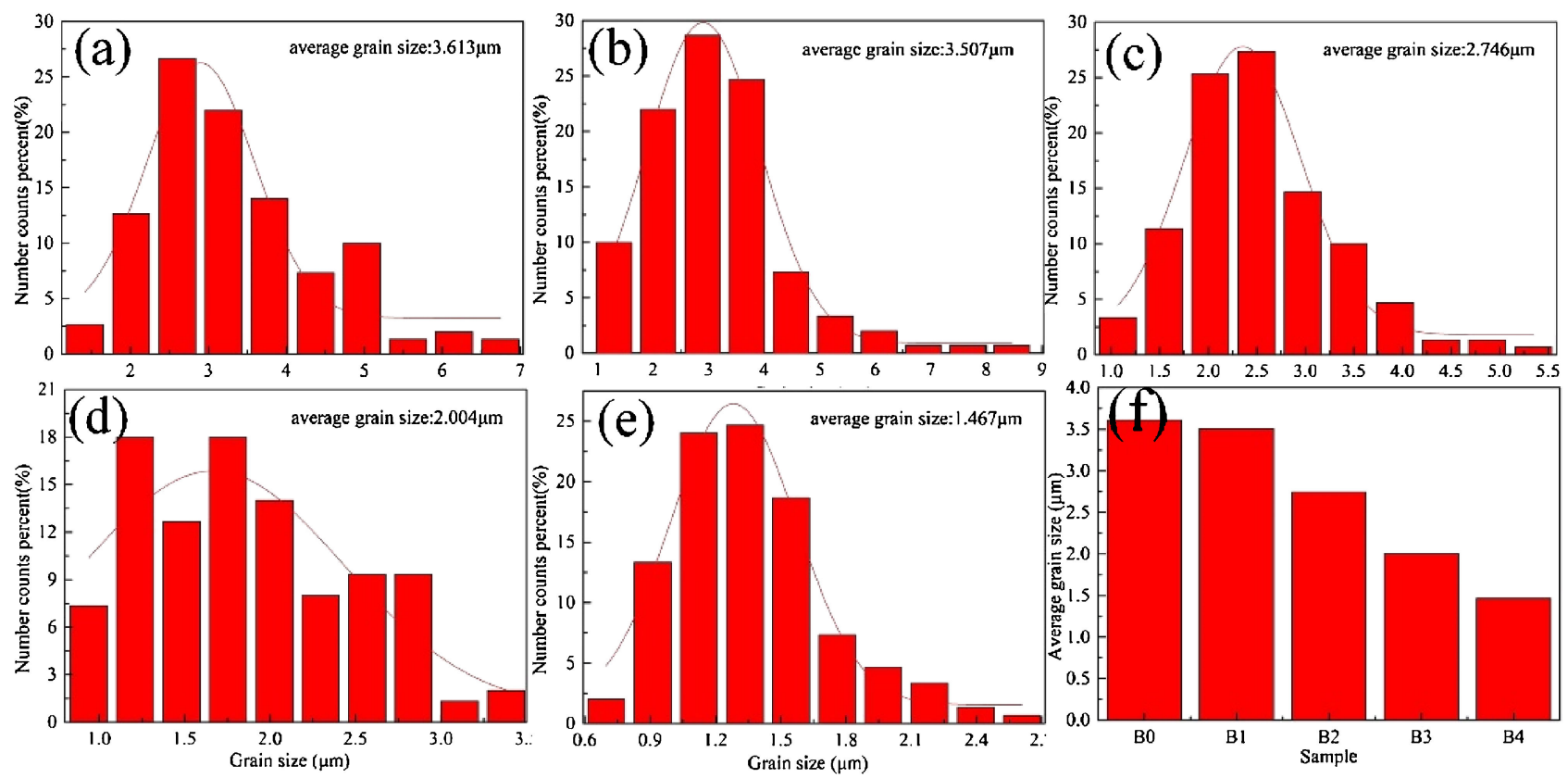

Fig. 8. Grain size distribution of ceramic phases of the Ti(C,N)- $x$ wt $\% \mathrm{TiB}_{2}-10 \mathrm{wt} \%$ HEAs composite cermets with different $\mathrm{TiB}_{2}$ mass content: (a) $0 \mathrm{wt} \%$, (b) $11.25 \mathrm{wt} \%$, (c) $15 \mathrm{wt} \%$, (d) $22.5 \mathrm{wt} \%$, (e) $45 \mathrm{wt} \%$, (f) average particle size. Each grain size has been measured more than 200 grains.

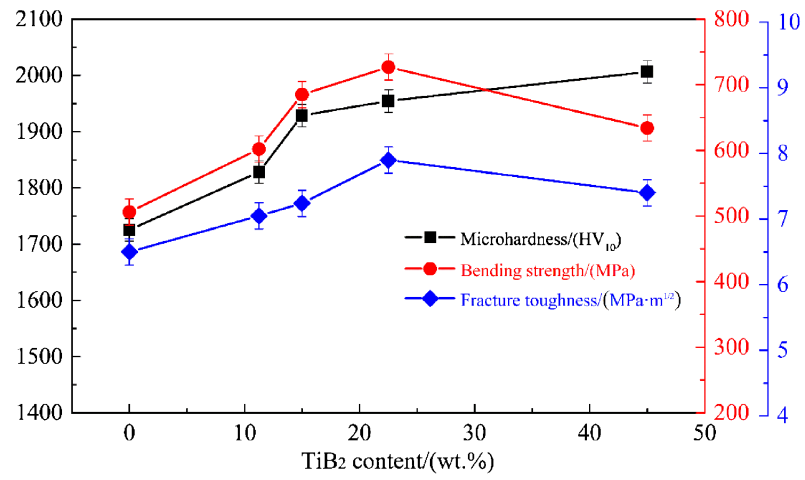

Fig. 9. The effect of $\mathrm{TiB}_{2}$ mass content on the mechanical properties of the $\mathrm{Ti}(\mathrm{C}, \mathrm{N})-\mathrm{TiB}_{2}-\mathrm{HEAs}$ composite cermets.

Because of these disadvantages, the sintering of pristine $\mathrm{TiB}_{2}$ requires a very high temperature (approximately $\left.2000^{\circ} \mathrm{C}\right){ }^{34)-36)}$ The relative density of $\mathrm{TiB}_{2}$ bulk ceramics was only $88 \%$, although the sintering temperature was as high as $2100^{\circ} \mathrm{C} .{ }^{37)}$ Therefore, with increasing $\mathrm{TiB}_{2}$ content to $45 \mathrm{wt} \%$, the insufficient sintering of the $\mathrm{TiB}_{2}$ had a dominant effect on the low relative density of the composite cermets.

Figure 9 shows the microhardness of the Ti(C,N)$x$ wt $\% \mathrm{TiB}_{2}-10 \mathrm{wt} \%$ HEAs composite cermets. With increasing $\mathrm{TiB}_{2}$ content, the microhardness increased gradually. When the $\mathrm{TiB}_{2}$ content increased to $45 \mathrm{wt} \%$, the microhardness reached a maximum of 2006.18 \pm 20 $\mathrm{HV}_{10}$. The hardness, relative density, and grain size of the ceramic have a synergistic effect on the hardness of the composite cermets materials. In this study, when the content was $0 \mathrm{wt} \%$, i.e., in the absence of $\mathrm{TiB}_{2}$, the grain size had a significant effect on the hardness. The lower hardness is attributed to the larger grain size and the lower hardness of the $\mathrm{Ti}(\mathrm{C}, \mathrm{N})$ compared to $\mathrm{TiB}_{2}$. Figure 8 shows that the average grain size reached $3.613 \mu \mathrm{m}$, and some coarse grains even reached 5-7 $\mu \mathrm{m}$, which could reduce the hardness according to the Hall-Petch formula. The process of grain growth was accomplished by the mutual annexation of grains, carried out through the gradual movement of grain boundaries. When the movement of a grain boundary meets second phase particles, its movement is hindered, thus reducing the grain growth rate. In the absence of $\mathrm{TiB}_{2}$, the material only had the $\mathrm{Ti}(\mathrm{C}, \mathrm{N})$ hard phase. The movement of the grain boundaries was not substantially hindered during the sintering process, resulting in the rapid growth of the grains. However, with increasing $\mathrm{TiB}_{2}$ content, the aggregation of the $\mathrm{Ti}(\mathrm{C}, \mathrm{N})$ particles decreased; therefore, the growth of the crystal grains decreased. ${ }^{33)}$ With increasing $\mathrm{TiB}_{2}$ content from 11.25 to $22.5 \mathrm{wt} \%$, the ceramic hardness and relative density had a synergistic effect on the hardness. The high relative density (Fig. 7) increased the bearing capacity of the matrix material. ${ }^{14)}$ When the $\mathrm{TiB}_{2}$ content further increased to $45 \mathrm{wt} \%$, the material obtained the highest hardness in this study, mainly attributed to the dominant role of high hardness $\mathrm{TiB}_{2}$ even though it had a low density.

Figure 9 shows the bending strength of the Ti $(\mathrm{C}, \mathrm{N})-$ $x$ wt $\% \quad \mathrm{TiB}_{2}-10$ wt $\%$ HEAs composite cermets. With increasing $\mathrm{TiB}_{2}$ content from 0 to $45 \mathrm{wt} \%$, the bending strength first increased to $727 \pm 20 \mathrm{MPa}$ and then decreased. In general, porosity and grain size have a primary effect on the bending strength of a material. ${ }^{14), 19), 38)}$ Equations (2) and (3) ${ }^{28), 29)}$ describes the relationship between the bending strength and porosity and grain size of a material: 

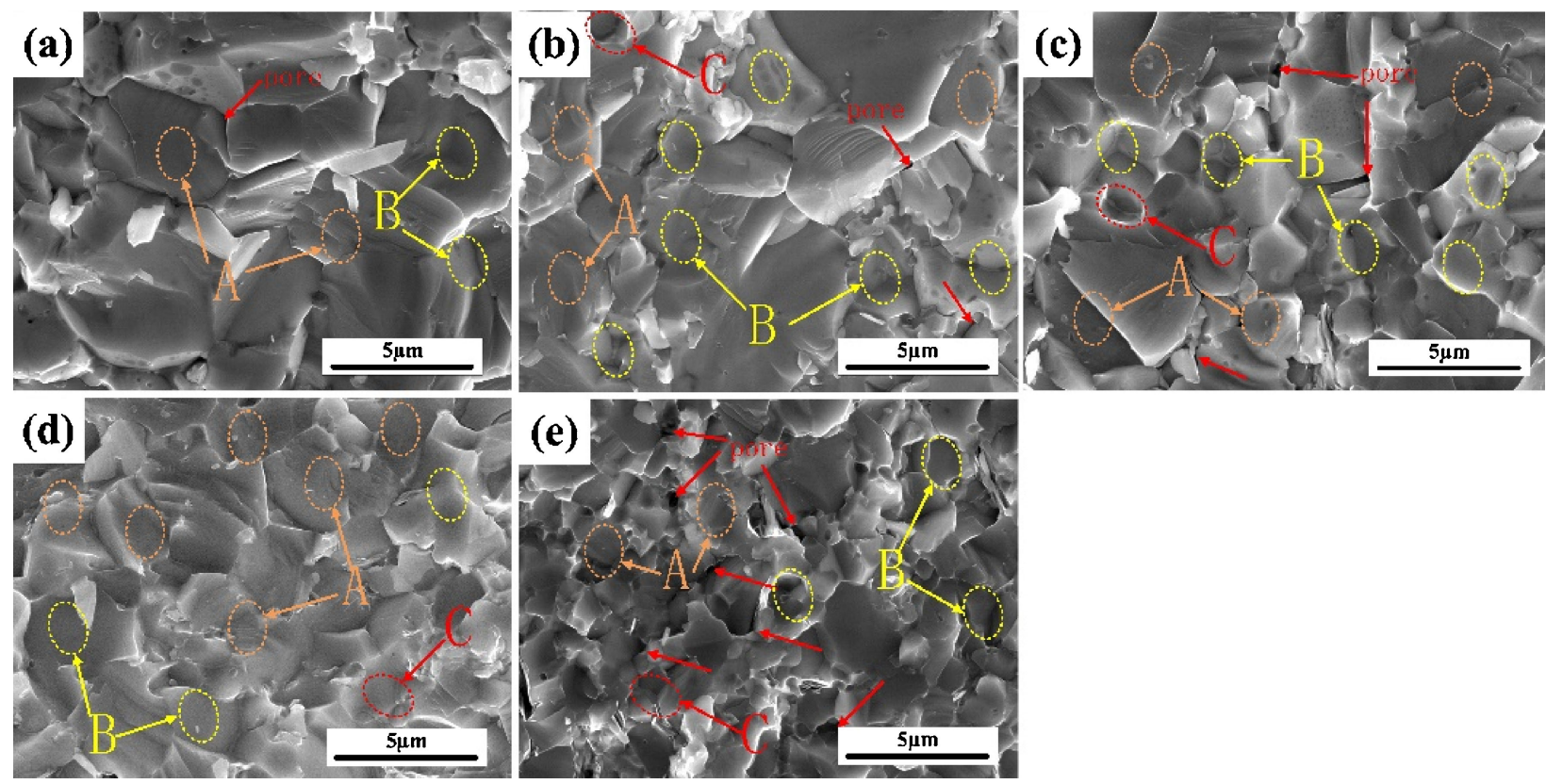

Fig. 10. The fracture surfaces SEM images of the sintered $\mathrm{Ti}(\mathrm{C}, \mathrm{N})-x \mathrm{TiB}_{2}-10 \mathrm{wt} \%$ HEAs composite cermets with different $\mathrm{TiB}_{2}$ mass content: (a) $0 \mathrm{wt} \%$, (b) $11.25 \mathrm{wt} \%$, (c) $15 \mathrm{wt} \%$, (d) $22.5 \mathrm{wt} \%$, (e) $45 \mathrm{wt} \%$.

$$
\begin{aligned}
& \sigma=\sigma_{0} \exp (-k \alpha) \\
& \sigma=\sigma_{0}+k d^{-m}
\end{aligned}
$$

where $\sigma$ is the strength of the material, $\sigma_{0}$ is the strength of the material, $\alpha$ is the residual porosity, $d$ is the grain size; $k$ and $m$ are the experimental coefficients. The formulas indicate that the bending strength of a material has a positive correlation with porosity and negative correlation with grain size. This function is in accordance with the experimental results of the bending strength. When the $\mathrm{TiB}_{2}$ content was $0 \mathrm{wt} \%$, the relative density was the highest, and when the content was $45 \mathrm{wt} \%$, the grain size was the smallest. However, both bending strengths were relatively low, which could be attributed to the dominant effect of former relatively large grain size and later relatively low density. Truly, the bending strength is relatively low for this study. The main reasons are that the oxygen $(0.45 \%)$ of FeCoCrNiAl HEAs binder results in the formation of $\mathrm{Al}_{2} \mathrm{O}_{3}$ in the grain boundary. In addition, compared to SPS, VHPS has a longer holding time at high temperature, promoting the formation of a small amount of brittle phase $\left(\mathrm{Fe}_{2} \mathrm{~B}\right)$, which will have a negative effect on the wetting of HEAs and $\mathrm{Ti}(\mathrm{C}, \mathrm{N})$ or $\mathrm{TiB}_{2}$ and lead to the existence of pores. Therefore, the bending strength is relatively poor. These analyses of the reasons for the relatively low bending strength have been supplemented in the manuscript. The material enhancement studies will be investigated in the future research.

Figure 10 shows the fracture surface images obtained from the SEM of the Ti $(\mathrm{C}, \mathrm{N})-x$ wt $\% \mathrm{TiB}_{2}-10 \mathrm{wt} \%$ HEAs composite cermets after the bending strength test. In Fig. 17, obviously, the mainly fracture modes of the composite cermets is transgranular fracture (area A, Fig. 10) and intergranular fracture (area B, Fig. 10). The pull-out grains (area C, Fig. 10) were also observed. Intergranular fracture might result in poor mechanical properties, because of the weak bonding of the ceramic particles. ${ }^{35)}$ However, when transgranular fracture emerged, the material might process excellent mechanical properties. This is mainly because high energy barrier needs to be overcame, when cracks propagate across the ceramic particles. ${ }^{14)}$

Figure 9 shows the function of fracture toughness as a function of $\mathrm{TiB}_{2}$ content. The fracture toughness and fracture strength had similar tendencies. As the $\mathrm{TiB}_{2}$ content increased from 0 to $45 \mathrm{wt} \%$, the fracture toughness of composite cermets increased first to the maximum value of 7.9 $\mathrm{MPa} \mathrm{m}^{1 / 2}$ and then decreased. The fracture toughness is well known to indicate the ability of a material to resist the crack propagation. ${ }^{40)}$ In general, toughening effects during crack propagation include crack deflection, branching, and surface peeling. ${ }^{8)}{ }^{40)}$ The porosity, grain size, and hard particles in the material have important effects on the crack propagation, ${ }^{41)-43)}$ and they also affect the fracture toughness of the composite cermets. Figure 11 shows the crack propagation pattern of the $\mathrm{Ti}(\mathrm{C}, \mathrm{N})-x \mathrm{wt} \% \mathrm{TiB}_{2}-10 \mathrm{wt} \%$ HEAs composite cermets. When the $\mathrm{TiB}_{2}$ content was $22.5 \mathrm{wt} \%$, transgranular fracture $\left(\mathrm{TiB}_{2}\right.$ particles $)$ and crack deflection were found during the crack propagation process. Crack deflection increases the mean free path of the crack, consumes more fracture energy, and ultimately improves the fracture toughness of the composite cermets. ${ }^{40)}$

\section{Conclusions}

The effect of the $\mathrm{TiB}_{2}$ content on the microstructure and mechanical properties of $\mathrm{Ti}(\mathrm{C}, \mathrm{N}) \mathrm{TiB}_{2}-\mathrm{FeCoCrNiAl}$ HEAs composite cermets was investigated. Based on the above results and discussion, the following conclusions were drawn: 

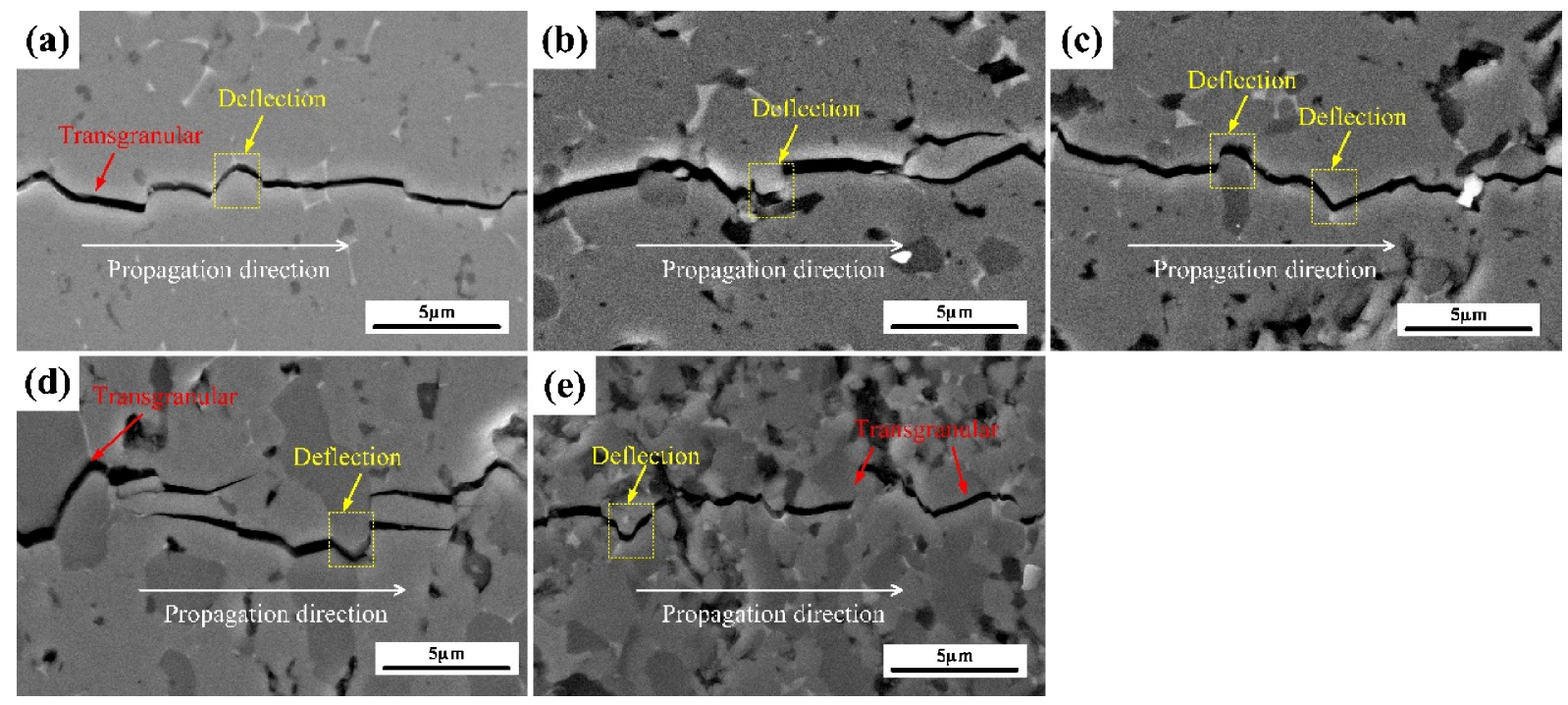

Fig. 11. Crack propagation path of the $\mathrm{Ti}(\mathrm{C}, \mathrm{N})-x \mathrm{TiB}_{2}-10 \mathrm{wt} \%$ HEAs composite cermets with different $\mathrm{TiB}_{2}$ mass content: (a) $0 \mathrm{wt} \%$, (b) $11.25 \mathrm{wt} \%$, (c) $15 \mathrm{wt} \%$, (d) $22.5 \mathrm{wt} \%$, (e) $45 \mathrm{wt} \%$.

(1) A small amount of $\mathrm{Fe}_{2} \mathrm{~B}$ was detected besides the $\mathrm{Ti}(\mathrm{C}, \mathrm{N})$ and $\mathrm{TiB}_{2}$ phase. The HEAs binder phase was tightly bound to $\mathrm{Ti}(\mathrm{C}, \mathrm{N})$ and $\mathrm{TiB}_{2}$, and the $\mathrm{Al}_{2} \mathrm{O}_{3}$ phase formed in the grain boundary.

(2) The microstructure of $\mathrm{Ti}(\mathrm{C}, \mathrm{N})-\mathrm{TiB}_{2}-\mathrm{FeCoCrNiAl}$ HEAs composite cermets was greatly affected by the $\mathrm{TiB}_{2}$ mass content. With increasing $\mathrm{TiB}_{2}$ content, the grain size decreased gradually, and the density first increased and then decreased.

(3) The hardness, relative density, and grain size of the ceramic had a common effect on the mechanical proper-

ties of the Ti(C,N)-TiB ${ }_{2}-\mathrm{FeCoCrNiAl}$ HEAs composite cermets. When the $\mathrm{TiB}_{2}$ content was either 0 or $45 \mathrm{wt} \%$, the grain size and density had a dominant effect on the mechanical properties. With increasing $\mathrm{TiB}_{2}$ content, the hardness increased gradually, and the bending strength and fracture toughness first increased and then decreased.

(4) When the $\mathrm{TiB}_{2}$ content reached $22.5 \mathrm{wt} \%$, the composite cermets exhibited excellent comprehensive performance, and the relative density, Vickers hardness, fracture toughness and bending strength reached $98.86 \pm 0.20 \%, 1954.4 \pm 20 \mathrm{HV}_{10}, 7.9 \pm$ $0.1 \mathrm{MPa} \mathrm{m}^{1 / 2}$, and $727 \pm 20 \mathrm{MPa}$, respectively.

Acknowledgments This work was supported by National Natural Science Foundation of China [Grant Number 51701040].

\section{References}

1) A. Rajabi, M. J. Ghazali and A. R. Daud, Mater. Design, 67, 95-106 (2015).

2) W. Ji, B. Zou, S. Zhang, H. Xing and H. Yun, J. Alloy. Compd., 732, 25-31 (2018).

3) Q. Xu, J. Zhao and X. Ai, Ceram. Int., 43, 6286-6294 (2017).
4) Q. Xu, X. Ai, J. Zhao, F. Gong, J. Pang and Y. Wang, J. Alloy. Compd., 644, 663-672 (2015).

5) J. Joardar, S. W. Kim and S. Kang, Mat. Sci. Eng. A-Struct., 360, 385-389 (2003).

6) P. Zhang, W. Sun, Q. Yang, P. Li and X. She, Mater. Sci. Forum, 810, 438-442 (2015).

7) Q. Xu, J. Zhao, X. Ai, W. Qin, D. Wang and W. Huang, J. Alloy. Compd., 649, 885-890 (2015).

8) H. Yu, Y. Liu, Y. Jin and J. Ye, Int. J. Refract. Met. H., 29, 586-590 (2011).

9) J. Xiong, Z. Guo, B. Shen and D. Cao, Mater. Design, 28, 1689-1694 (2007).

10) H. Xiong, Y. Wen, X. Gan, Z. Li and L. Chai, Mat. Sci. Eng. A-Struct., 682, 648-655 (2017).

11) A. Demoly, W. Lenguar, C. Veitsh and K. Rabitsh, Int. J. Refract. Met. H., 29, 716-723 (2011).

12) Y. J. Zhao, Y. Zheng, W. Zhou, J. J. Zhang, Q. Huang and W. H. Xiong, Ceram. Int., ○○ , 425487-5496 (2016).

13) H. Suzuki, K. Hayashi and Y. Taniguchi, Trans. Jpn. Int. Met., 22, 312-319 (1983).

14) N. Wu, F. Xue, J. Wang, H. Yang, F. Luo and J. Ruan, Mat. Sci. Eng. A-Struct., 743, 546-557 (2019).

15) L. Zhang, H. Y. Wang, S. T. Li, C. Liu and Q. C. Jiang, J. Alloy. Compd., 468, 143-149 (2009).

16) Y. Zhang, T. Ting, Z. Tang, M. C. Gao, K. A. Dahmen, P. K. Liaw and Z. Ping, Prog. Mater. Sci., 61, 1-93 (2014)

17) J. W. Yeh, S. Chen, S. Lin, J. Gan, T. Chin, T. Shun and C. Tsau, Adv. Eng. Mater., 6, 299-303 (2004).

18) W. Ji, J. Zhang, W. Wang, H. Wang, F. Zhang, Y. Wang and Z. Fu, J. Eur. Ceram. Soc., 35, 879-886 (2014).

19) G. Zhu, Y. Liu and J. Ye, Int. J. Refract. Met. H., 44, 35-41 (2014).

20) C. Chen, C. Yang, H. Chai, J. Yeh, J. Lik and H. Chau, Int. J. Refract. Met. H., 43, 200-204 (2014).

21) P. L. Zhou, D. H. Xiao, P. F. Zhou and T. C. Yuan, Ceram. Int., 44, 0-1 (2018).

22) Z. He and M. Wang, Rare Metals, 36, 494-500 (2017).

23) E. Shankar and S. B. Prabu, Ceram. Int., 43, 10817- 
10823 (2017).

24) L. Wang, H. Liu, C. Huang, B. Zou and X. Liu, Ceram. Int., 40, 16513-16519 (2014).

25) Z. Wang, B. Xie, W. Zhou, G. Shi and Z. Wu, Int. J. Refract. Met. H., 41, 609-613 (2012).

26) Y. Wang, S. Shu, F. Qiu, D. Zhou, J. Wang and Q. Jiang, Mater. Design, 45, 286-291 (2013).

27) T. Venkateswaran, B. Basu, G. B. Raju and D. Kim, J. Eur. Ceram. Soc., 26, 2431-2440 (2006).

28) N. Wu, F. Xue, H. Yang, G. Li, F. Luo and J. Ruan, Ceram. Int., 45, 1370-1378 (2019).

29) S. Zhang, Y. Sun, B. Ke, Y. Li, W. Ji, W. Wang and Z. Fu, Metals, 8, 58 (2018).

30) K. Niihara, J. Mater. Sci. Lett., 2, 221-223 (1983).

31) Y. Xie, H. Cheng, Q. Tang, W. Chen, W. Chen and P. Dai, Intermetallics, 93, 228-234 (2018).

32) W. Ji, Z. Fu, W. Wang, H. Wang, J. Zhang, Y. Wang and F. Zhang, J. Alloy. Compd., 589, 61-66 (2014).

33) A. Mukhopadhyay, T. Venkateswaran and B. Basu, Scripta Mater., 69, 159-164 (2013).
34) Z. Fu and R. Koc, Ceram. Int., 44, 9995-9999 (2018).

35) B. Basu, G. B. Raju and A. K. Suri, Int. Mater. Rev., 51, 352-374 (2006)

36) S. Baik and P. F. Becher, J. Am. Ceram. Soc., 70, 527530 (1987).

37) M. Halasová, E. Neubauer, H. Hadraba, N. Stelzer and P. Roupcová, J. Eur. Ceram. Soc., 35, 2745-2754 (2015).

38) E. Shankar, S. B. Prabu and K. A. Padmanabhan, J. Aust. Ceram. Soc., 54, 565-574 (2018).

39) W. Wang, Z. Fu, H. Wang and R. Yuan, J. Eur. Ceram. Soc., 22, 1045-1049 (2002).

40) H. Liu, Y. Chai, C. Huang, H. Liu and J. Wang, Ceram. Int., 41, 2813-2818 (2015).

41) T. Zhou and C. Huang, Comput. Mater. Sci., 104, 177184 (2015).

42) C. C. Wu, S. W. Freiman, R. W. Rice and J. J. Mecholsky, J. Mater. Sci., 13, 2659-2670 (1987).

43) P. F. Becher, Toughening Mechanisms in Quasi-Brittle Materials, 19-33 (1991). 